\title{
El cine intelectual de Fernando Birri. Antecedentes a la conformación del Documental Militante en Argentina
}

\section{Romero Zurita, Antonio}

\section{Resumen:}

El cine argentino tiene una historia marcada por el accionar de grandes cineastas. Fernando Birri es uno de ellos. Natal de Santa Fe, este cineasta propuso desde su obra una mirada ética y estética que permitió el auge de una identidad local y regional. Identidad que posteriormente se reproduce magníficamente en el llamado Tercer Cine y en la tradición del cine militante. La obra de Birri, analizada desde sus primeras películas, evidencia un eje conceptual adscrito a la contra hegemonía. En este sentido, la obra de Birri se devela desde un pensamiento cargado de un compromiso político hacia la transformación social.

\section{Cuadernos del Centro de Estudios de Diseño y Comunicación N N 62}

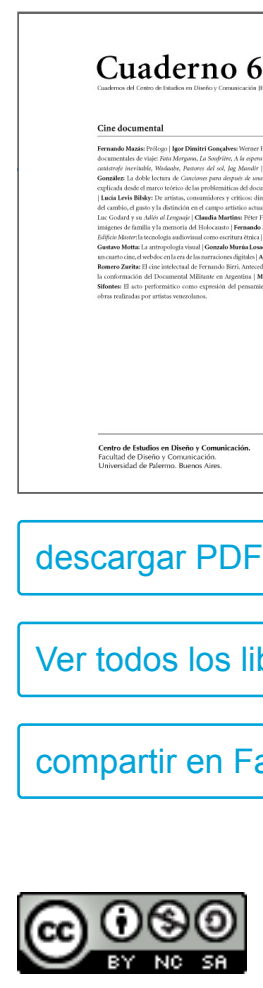

Esta obra está bajo una Licencia Creative Commons Atribución-NoComercialCompartirlgual 4.0 Internacional

Palabras claves: Fernando Birri - hegemonía - contra hegemonía - intelectual - cine - militante.

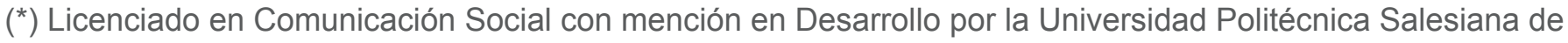
Quito. Desde el 2014 estudiante de la Maestría de Cine Documental de la Universidad del Cine (FUC).

Introducción

El rol del intelectual en la conformación, ética y estética, del cine documental latinoamericano significa un antecedente importante para entender de mejor manera la producción audiovisual contemporánea y, en el caso de este estudio, la producción del documental militante en la Argentina.

Esta monografía tiene como tarea detallar un marco histórico que permita reflexionar sobre la prevalencia del pensamiento contra hegemónico en la obra de Fernando Birri y connotar, su ética y estética, como antecedente fundamental para la conformación del denominado Cine Militante. 
Me propongo este análisis pues mi tema de tesis tiene por objeto reflexionar sobre lo ético, político e ideológico en el documental contemporáneo, particularmente en la producción de los documentalistas militantes y videoactivistas argentinos.

Me interesa reflexionar sobre la tradición que refiere la experiencia del cine intelectual, critico y popular de Birri para poder, en algún sentido, relacionarlo con nociones ético, políticas que determinen antecedentes para una pensar la prevalencia de la militancia documental en la actualidad.

Considero a Fernando Birri, referente en la historia del cine argentino, personaje a quien le debo gran admiración por su historia fílmica así como por su tradición académica. Sin lugar a dudas realizar un texto sobre su obra y pensamiento refiere un grado de valor sobre el rol del intelectual en la conformación de lenguajes y discursos políticos en la sociedad.

\section{Desarrollo}

El cine en América Latina se asentó, mayormente, en aquellos países cuya economía y desarrollo industrial permitió el crecimiento y florecimiento de la industria cinematográfica.

Argentina, Brasil y México fueron los países que recibieron en el seno de su historia al dispositivo cinematográfico y llevarán, hasta la actualidad, la batuta en la producción audiovisual regional.

El cine en Argentina se produce muy tempranamente, a inicios del siglo XX, la intensa migración europea potenció la importación del novedoso cinematógrafo de los hermanos Lumiere al territorio argentino.

Hacia finales de la década de 1920, la Argentina tendría un desarrollo cinematográfico muy intenso y rápido. A partir de la década de los 30, debido a la necesidad de producir insumos técnicos y dado el auge del cine en el país fueron apareciendo las grandes productoras, que generaban, películas en forma ininterrumpida.

Los jóvenes estudios de cine argentinos tenias como objetivo emular a sus pares de Hollywood como sitio de filmación.

La década de los años 30 otorga importantes ejemplos de un cine destinado al consumo de las clases medias y altas. Caracterizado por la presencia de comedias livianas, protagonistas ingenuas y escenarios fastuosos el cine argentino daba lugar al llamado "cine de teléfonos blancos".

Llegada la década de los 40 el cine empieza a vivir una transformación, esto en parte debido a la llegada de Perón al poder, situación que permitió que grandes sectores populares adquirieran por primera vez en la historia protagonismo en la vida política nacional y que la "Argentina invisible" hiciera su irrupción en el escenario social.

Para la década de los 50 el cine denominado moderno ya proponía antecedentes para la conformación del Nuevo Cine Argentino, movimiento que tendrá entre otros cineastas a Fernando Birri como protagonista. Al respecto, Emilio Bernini en su texto La vía política del cine argentino. (Bernini, 2001) A partir de mediados de los años cincuenta, los cineastas dejan de mantener una serie de vínculos pautados por la producción industrial, y con ello asumen otro rol en relación con sus producciones y con la sociedad. (Bernini, 2001, 41) Es importante referir, que este marco en la producción cinematográfica argentina, donde el realizador empieza a cuestionarse 
sobre los medios de producción cinematográficos propone, en algún sentido, un avance en la consideración del rol ético social del cine, como se vera mas adelante en el detalle de la obra de Birri.

Para continuar y completar en algún sentido esta breve reseña del cine argentino, la historia del cine documental tiene una historia no tan fastuosa ni acaudalada como su par de ficción en la Argentina. Pequeñas producciones, particularmente noticiosos y eventos históricos son escenario del cine de lo real cuya presencia no tendrá mayor auge previo a la década de los 50.

La edad de Oro del Cine, conocido de esta manera por la cantidad de películas producidas, es el reflejo de una generación de cineastas, con ciertas excepciones, productores de un cine de carácter neutro y funcional a la cultura dominante.

No es ingenuo pensar que el cine, al ser un producto ideológico (Comolli, 1971), particularmente el cine de ficción, a contribuido a la conformación de la cultura dominante y es parte protagónica del ejercicio de dominación a través de la reproducción del pensamiento hegemónico.

En este punto considero importante reflexionar acerca de la categoría hegemonía.

En este sentido, hegemonía como diría Raymond Williams en su texto Literatura y Marxismo (1997), es un vivido sistema de significados y valores sobre lo absoluto.

La hegemonía constituye todo un cuerpo de prácticas y expectativas en relación con la totalidad de la vida: nuestros sentidos y dosis de energía, las percepciones definidas que tenemos de nosotros mismos y de nuestro mundo. Es un vivido sistema de significados y valores -fundamentales y constitutivos- que en la medida en que son experimentados como practicas parecen conformarse recíprocamente. Por lo tanto es un sentido de la realidad para la mayoría de las gentes de la sociedad, un sentido de lo absoluto... es una "cultura" pero una cultura que debe ser considerada asimismo como la vivida dominación y subordinación de clases particulares. (Williams, 1997, p. 131) El pensamiento hegemónico presente, supone esta monografía, en las películas de la Edad De Oro del cine argentino, no solo por la técnica de los estudios cinematográficos, sino y sobre todo, por la visión estereotípica de Latinoamérica, ha conformado un imaginario social sobre la región, un lugar común de enunciación, un Latinoamérica folklórico vaciado de sentido.

Al respecto, la ideología capitalista se conforma de esta manera, gracias a la industria cultural que refiere el cine y a los campos de reproducción del pensamiento hegemónico, suponiendo a Latinoamérica como una porción sin historia, sin presente, ni ejercicio político.

Una lamentable reducción de la basta diversidad latinoamericana.

En este contexto, Fernando Birri en la Argentina, Glauber Rocha en el Brasil y Sánchez Alea en Cuba, aparecen en la historia del cine latinoamericano rompiendo, de alguna manera con los cánones técnicos, éticos y estéticos del llamado cine hegemónico. Ellos comprendieron que la realidad de América Latina debía de tener una presencia real, realista y social en la producción cinematográfica.

En este sentido, este texto intentará, a continuación desarrollar una lectura crítica de la obra de Fernando Birri con el objeto de relacionar la categoría de contrahegemónia a su producción. 
La obra de Birri, gestada a comienzo de la década de los 60 , se desarrolla en un contexto político y social donde el pensamiento liberal y de izquierda polarizaba fuertemente con el conservadurismo reinante de la región. El clima de post guerra, los primeros años de la revolución cubana, así como la influencia en términos artísticos del nuevo realismo italiano, conlleva a un cierto despertar intelectual en América Latina.

El cine de Fernando Birri, obra marcada por una impronta política, conjugó la débil tradición del cine critico realista del país con las aspiraciones libertarias de muchos jóvenes cineastas de la época. (Bustos, 2006, p. 33) El rol del intelectual en tiempo de transformación y de concienciación social, como bien se vivía en la década de los 60 , se manifiesta en una enunciación cercana a los interés de la clase obrera.

En este sentido, la labor creativa e intelectual de Birri, comprende su lugar dentro de la historia reciente de Latinoamérica y propone, sin manifestar explícitamente una simpatía por los procesos revolucionarios, un primer momento para repensar al Nuevo cine argentino, momento que tiene que ver con la toma de conciencia.

En la obra de Birri la huella realista potenciada desde la voz de los pobres y marginados, proyecta una cierta alineación de clase. El rol del intelectual, como lo señalaba Karl Manheim en su texto sobre la Intelligentsia, parte desde la comprensión dinámica que genera el hecho de no tener una clase social y de buscar encontrar un lugar dentro de la sociedad que permita justificar el campo de la creación.

Se puede resumir las características esenciales de esta capa social como sigue. Es un conglomerado entre, pero no sobre, las clases. El miembro individual de la "intelligentsia" puede tener, y con frecuencia tiene, una orientación particular de clase y, en conflictos reales, puede alinearse con uno u otro partido político.

Además, sus elecciones individuales pueden tener la consistencia y las características de una posición de clase perfilada. (Mannheim, 1957, p. 155) Birri personifica, en este sentido, la vanguardia del pensamiento intelectual que realiza cine en la Argentina.

El mismo que propone un rol ético del documental como texto político. Al respecto, se busca retratar la sociedad de la manera más real posible. Este hecho, que bien podría parecer más una opción estética, refleja en este sentido un compromiso ético proveniente de la lectura que propone la lucha de clases.

Los cineastas de los años sesenta son conscientes del uso del cine, de sus efectos sobre lo que va mas allá de el, y son conscientes también de que esos efectos pueden ser producidos con deliberación. Fernando Birri es uno de los primeros de ellos en responder a una demanda implícita, a la que responderán a su vez los cineastas modernos, por la que el cine debe ofrecer saberes sobre la sociedad argentina. (Bernini, 2001, p. 41) El hecho de construir un punto de vista divergente del oficial, reflexivo y a la vez confrontativo refleja la necesidad de fortalecer una identidad propia a partir del dispositivo documental. Siguendo la lectura de Bernini en su texto La via política del cine argentino, se evidencia en la obra del cineasta santafesino una necesidad de romper con los cánones hegemónicos de producción cinematográfica.

Tire Dié, y luego, Los Inundados se presentan así como síntesis de dos tendencias irreconciliables a lo largo de la historia, la de un cine falsamente popular o "populista" predominante, y la de aquella que surge en reacción, la del nuevo cine...El cineasta santafesino niega entonces la negación primera del nuevo cine, pero incluye el costado popular, y con ello, postula un tercer cine, aunque no tuviera ese nombre ni su sentido político: un cine 
popular e intelectual, realista y crítico" (Bernini, 2001, p. 41). La obra de Birri expresa, es este sentido, un encuentro estético frente al estereotipo hegemónico de producción cinematográfica. La idea de representar la realidad latinoamericana, refleja la elección de un punto de vista que discurre de la habitual estética fastuosa propuesta por los estudios cinematográficos.

En Tire Dié (1960) se relata la convivencia de dos contextos radicalmente opuestos en Santa Fe, provincia de la Argentina. La evidente diferenciación de clases es ironizada desde un lugar de enunciación cercano a la voz del pueblo.

La miseria y la opulencia debaten en Tire Die, film de media hora, donde la encuesta es utilizada para generar un texto social cuyo interés es representar a los invisibles. La palabra del campesino, del pobre, de la mujer, del niño, forma parte de un mensaje crítico cuya reflexividad propone un rol ético político del cine. Al respecto, la visión política de Birri ocupa en gran medida su motivación como cineasta, ya que, a criterio propio, el documentalismo, debía innovar en los aspectos formales, promoviendo una acción política de denuncia de la desigualdad.

La impronta ética y estética de Birri, referida a un campo externo más que interno, donde los códigos sociales reflejan la injusticia, inequidad, pobreza y miseria desarrolla un cine con claros elementos contrahegemónicos. En este sentido y retomando a Williams.

En la practica la hegemonía... no se da de modo pasivo como una forma de dominación.

Debe ser continuamente renovada, recreada, defendida y modificada.

Así mismo, es continuamente resistida, limitada, alterada, desafiada por presiones que de ningún modo le son propias. Por tanto debemos agregar al concepto de hegemonía los conceptos de contrahegemonia y de hegemonía alternativa, que son elementos reales y persistentes de la practica. (Williams, p. 134) El contenido que entrega Birri a la noción documental no solo se queda en confrontar a la noción de estudio; cercada por un imaginario folklorista del latinoamericano, sino que lo lleva a desarrollar un lenguaje, donde el audio y la imagen apuntan a un texto evidentemente político y cuestionador del estado de las cosas.

La enunciación critica que si bien es cierto, no deja de ser ligera o poética, detalla el deseo del realizador de aportar, desde su especialidad intelectual, a las transformaciones sociales de la época, además de inconscientemente, proponer avances teóricos para la determinación del Cine Militante.

El hecho de brindar un punto de vista comprometido, ética y estéticamente, con las clases sociales, apertura un campo de acción cinematográfico, donde la necesidad de intervenir la realidad que es contada propone un gran campo cuestionador del modelo dominante y del cine tradicional.

Para finalizar, en alguna ocasión alguien le pregunto a Fernando Birri. ¿Qué cine necesitan los pueblos subdesarrollados de Latinoamérica?. Ante lo cual contestó: Un cine que los desarrolle. Un cine que les dé conciencia, toma de conciencia; que los esclarezca; que fortalezca la conciencia revolucionaria de aquellos que ya la tienen; que los fervorice; que inquiete, preocupe, asuste, debilite, a los que tienen "mala conciencia", conciencia reaccionaria; que defina perfiles nacionales, latinoamericanos; que sea auténtico; que sea antioligárquico y antiburgués en el orden nacional y anticolonial y antimperialista en el orden internacional; que 
sea propueblo y contra antipueblo; que ayude a emerger del subdesarrollo al desarrollo, del subestómago al estómago, de la subcultura a la cultura, de la subfelicidad a lafelicidad, de la subvida a la vida. (Birri, 1962) Conclusión

El cine latinoamericano ha existido casi desde los inicios del cinematógrafo particularmente en países como Argentina y México. La historia del cine en esta región, concretamente aquel que se desarrolló a partir de la década de los 60, marca un punto divergente en el modo de producción cinematográfico donde no solo se propone una transformación en el complejo técnico sino además desde la enunciación social y el rol político del cine.

Partiendo de esta relación, el cine latinoamericano, particularmente el documental, asume la responsabilidad histórica de alejarse del estereotipo hollywoodense de producción y construirse a si mismo desde un contexto propio.

En Argentina, la experiencia del cine documental se conforma dentro de un campo, donde la representación de la violencia, marginalidad y miseria proponen una enunciación política que participa de criterios; en algunos casos denunciantes, en otros militantes y revolucionarios, los mismos que asumen un principio contra hegemónico para la realización.

Fernando Birri fue de los primeros intelectuales que se propuso realizar un cine con un grado divergente. Es decir, un cine que contenga elementos propios en la conformación del mensaje, un cine que no discurra por los habituales lugares de enunciación de América Latina, un cine cuyo objeto no sea solamente entretener e informar, sino más que todo generar conciencia.

Considero que el cine de Birri habla desde un contexto donde la teoría de izquierda empieza a ocupar ciertos campos determinados por las artes. En este sentido, la compresión de la lucha de clases, si bien no totalmente evidente en su obra, propone serios cuestionamientos al ejercicio histórico del cine mundial.

Creo que Fernando Birri, así como de otros grandes autores latinoamericanos, no lograron construir afinidad con las corrientes del cine soviético, del neorealismo italiano, del cinema verite, (campos abiertos a la experimentación, a la denuncia social y de frontal unidad anti-industrial) que no lograron responder a las necesidades ético-políticas de los realizadores sudamericanos, quienes enuncian un campo de descolonización contextualizado en la realidad socio política de América Latina.

Sin embargo, considero que la misma noción intelectual y popular, si bien permite la generación de pensamiento crítico y evidencia la determinación de un campo de la sociedad, no alcanza para concretar los objetivos descolonizantes en las relaciones sociales, situación que es parte fundamental de la impronta del cine de Birri.

La conciencia de clase, límite constitución del rol del intelectual, será la única herramienta para la determinación de un campo político de acción revolucionaria.

Este marco, que si bien es cierto no es mencionado por Birri, tampoco tiene gran apego en el ejercicio político de su cine documental. 
La realización de esta monografía me ha permitido valorar, en cierto sentido, los aportes de Birri respecto a la practica documental. Considero importante comprender el rol del intelectual no solo para la generación de conocimiento, sino además para facultar la convocatoria y convergencia de las nuevas generaciones en pro de la consecución de una tradición.

Al respecto, Pierre Bourdieu, en el Oficio del Sociólogo.

Las oposiciones en torno a las cuales se organiza las luchas [...] pueden, en última instancia, reducirse a la oposición entre los jóvenes, es decir, los recién llegados, los que acaban de entrar, y los viejos, los que están establecidos [...] estas oposiciones marcan finalmente la oposición entre edades y generaciones artísticas, es decir entre posiciones diferentes dentro del campo artístico. [...] El hecho de entrar en el juego de la producción, de existir intelectualmente, significa que uno hace época, y, al mismo tiempo, remite al pasado a todos aquellos que también hicieron época en su momento.

(Bourdieu, 1990, p. 138) La tradición social que funda Birri potencia un legado que es heredado por todos los movimientos de cine militante argentino hasta la actualidad.

El reflejo de las nuevas generaciones, quienes relacionan, el pasado con el presente configuran lo que Raymond Williams denomina tradición de orden selectiva (Williams, 1997).

Una visión intencionalmente selectiva de un pasado configurativo y un presente pre configurado, que resulta entonces poderosamente operativa dentro del proceso de definición e identificación social (Williams, 1997) En este sentido el aporte de la historia del cine de Fernando Birri se evidencia en la conformación de una lectura de continuidad y ruptura en el interior del campocinematográfico argentino, donde la formación cultural de un movimiento cinematográfico emergente se manifiesta en la gestación de nuevos imaginarios sociales del arte y la política.

En el caso del campo cinematográfico las posteriores experiencias de Cine Liberación y Cine de la Base en los años 70, y de los videoactivistas argentinos, Alavio Films, Contraimagen, Cine Insurgente, a partir de los 90 y principios del siglo XXI detallan un conjunto de valores estéticos y éticos, culturales e ideológicos vinculados a la interpretación intelectual de Fernando Birri.

\section{Bibliografía}

Bernini, E. (2001). “La via política del cine argentino”. Kilometro 111, Ensayos sobre cine, N. 2. Buenos Aires.

Comolli, J-L. (1971). Tecnica e Ideología. Buenos Aires: Manantial.

Bustos, G. (2006). Audiovisuales de combate. Acerca del videoactivismo contemporáneo, Buenos Aires: La Crujía.

Bourdieu, P. (1990). "La metamorfosis de los gustos”, en Bourdieu, P. Sociología y Cultura. México: Grijalbo.

Williams, R. (1997). Marxismo y Literatura. Barcelona: Península. 
Mannheim, K. (1957). Ensayos de Sociología de la Cultura. Madrid: Aguilar.

Birri, F. (1962). Cine y Subdesarrollo. Disponible en: https://es.scribd.com/doc/47574559/FERNANDO-BIRRICine-y-Subdesarrollo

\section{Abstract:}

Fernando Birri is a film maker and theorist. He is considered by many to be the father of the new Latin American cinema. Birri was born in Santa Fe, Argentina. He proposed from his work and ethic and aesthetic approach that allowed the raise of a local and regional identity. That identity is reproduced afterwards in the Third cinema and in the activist cinema tradition. Birri's work, analyzed from his first films, shows a conceptual axe alined with the anti hegemony. In this sense, the work of Birri is revealed from a thought loaded with political commitment to social transformation.

Key words:

Fernando Birri - hegemony - non-hegemony - intelectual - cinema - activist.

\section{Resumo:}

O cinema argentino tem uma historia marcada pela atuação de grandes cineastas. Fernando Birri é um deles. Nascido em Santa Fé, este cineasta propôs desde sua obra uma mirada ética e estética que permitiu o auge de uma identidade local e regional. Identidade que depois se reproduz no denominado Terceiro Cinema e na tradição do cinema militante. A obra de Birri, analisada desde seus primeiros filmes, evidencia um eixo conceitual aderido à contra hegemonia. Neste sentido, a obra de Birri revela-se desde um pensamento carregado de um compromisso político até a transformação social.

Palavras chave:

Fernando Birri - hegemonia - contra-hegemonia - intelectual - cinema - militante.

El cine intelectual de Fernando Birri. Antecedentes a la conformación del Documental Militante en Argentina fue publicado de la página 107 a página114 en Cuadernos del Centro de Estudios de Diseño y Comunicación № 62 